\title{
New ion exchange membrane derived from sulfochlorated polyether sulfone for electrodialysis desalination of brackish water
}

\author{
Walid Mabrouk $^{1}$ (D) | Ridha Lafi ${ }^{1}$ ～Jean François Fauvarque ${ }^{2}$ | Amor Hafiane ${ }^{1}$ | \\ Cyrille Sollogoub ${ }^{3}$
}

\author{
${ }^{1}$ Laboratory Water, Membranes and \\ Biotechnology of the Environment, CERTE, \\ Soliman, Tunisia \\ ${ }^{2}$ Industrial Polymer Materials Laboratory, \\ CNAM, Paris, France \\ ${ }^{3} \mathrm{PIMM}$, Arts and Metiers Institute of \\ Technology, CNRS, Cnam, HESAM University, \\ Paris, France \\ Correspondence \\ Walid Mabrouk, Laboratory Water, \\ Membranes and Biotechnology of the \\ Environment, CERTE, Soliman 8020, Tunisia. \\ Email:w.mabroukcerte@gmail.com \\ Funding information \\ ERAS Labo; World Health Organization
}

\begin{abstract}
The purpose of this work is to study the desalination of brackish water using a new ion exchange membrane, made from sulfochlorated polyethersulfone (Cl-PES), and crosslinked using aminated polyethersulfone (NH2-PES) as a crosslinking reagent. This membrane, named $\mathrm{CINH} 2$ membrane, has been obtained by reaction between $\mathrm{Cl}$-PES with $1.3 \mathrm{SO}_{2} \mathrm{Cl}$ groups per monomer unit and 0.2 equivalent amount of $\mathrm{NH} 2-\mathrm{PES}$. CINH2 membrane has been characterized in terms of contact angle, transport number, intrinsic conductivity, and water uptake (as a function of temperature). Electrodialysis performances of the newly synthetized membranes have been measured using an electrodialysis cell at a laboratory scale and compared to commercial membranes. All the experiments have been performed using synthetic brackish water solutions prepared from sodium chloride salts with different concentrations (varying from 0.5 to $5.0 \mathrm{~g} / \mathrm{L}$ ). The concentration of different water samples obtained has been found to be below the amount recommended by the World Health Organization (WHO) for drinking water.
\end{abstract}

\section{KEYWORDS}

$\mathrm{CINH} 2$ membrane, conductivity, demineralization rate, desalination, electrodialysis, ion exchange membrane, ionic flux transport

\section{1 | INTRODUCTION}

Water is a vital and indispensable resource in various sectors. ${ }^{1}$ Nevertheless, shortage of drinking water is a serious issue throughout the world, especially because of an increase in water demand, combined with population growth and economic development. ${ }^{2-4}$ Several membrane processes, like ultrafiltration (UF), nanofiltration (NF), microfiltration (MF), reverse osmosis (RO), and electrodialysis (ED) can greatly alleviate water shortage issues by producing potable water from seawater, wastewater, and brackish water. ${ }^{5-7}$ Among these processes, we can provide both fresh, pleasant water and table salt from saltwater with the help of ion exchange membranes (IEM). These membranes are in the form of thin and uniform sheets, containing fixed electrical charges, that reject the ions with the same charge.,
According to the need, the membrane should have a relatively high water uptake, an excellent ion exchange capacity, and good thermal and mechanical stabilities. The long-term stability of the membrane and the thermal stability are of prime importance in ED that may operate at temperatures up to $80^{\circ} \mathrm{C} .^{10-13}$

To date, many polymers have been used in the preparation of IEMs, for example, polystyrene, ${ }^{14}$ polyetherimide, ${ }^{15}$ polyetherther ketone ${ }^{16}$ polyetherbenzimidazole, ${ }^{17}$ and polyarylene ether. ${ }^{18,19}$ These membranes have been used for distinct applications, for example, in biomedical, $^{20}$ pervaporation, ${ }^{21}$ fuel cell, ${ }^{22-24}$ desalination, ${ }^{25}$ electrodialysis, ${ }^{26}$ electrolysis, ${ }^{27}$ nanofiltration, ${ }^{28}$ etc.

Preparing homogeneous exchange membranes with convenient properties for electrodialysis application was the major target of our current research. In this study, we used a membrane based 
on polyethersulfone, which can be easily sulfonated to obtain sulfonated polyethersulfone (S-PES) or Chloro-sulfonated. ${ }^{18,19}$ The functionalization, by (chloro)sulfonation of these polymers, led to improved membrane properties in terms of perm-selectivity, and ion conductivity. In order to prevent solubilization and to increase the mechanical stability of the membranes, crosslinking has been found to be very efficient. In particular, membranes crosslinked with $\mathrm{NH} 2-\mathrm{PES}$ as crosslinking agent (named CINH2) displayed excellent thermal, electrochemical properties, and good performances in proton exchange membrane fuel cell (PEMFC). ${ }^{19}$

In this paper, we have investigated the performances of these membranes in electrodialysis. Some new characterizations of the $\mathrm{CINH} 2$ membrane with 1.1 protons per monomer unit have been performed: contact angle, ionic exchange capacity, water uptake, etc. Furthermore, the electrodialysis performances using $\mathrm{CINH} 2$ membrane have been investigated and compared with those obtained with the commercial membrane (PC-SK).

\section{2 | EXPERIMENTAL METHODS}

\section{1 | Materials}

Sulfochlorated polyether sulfone and aminated polyether sulfone were synthesized at Eras Labo. N,N'-dimethylacetamide (DMAc) was purchased from Acros. Sulfuric acid was purchased from Scharlau. Sodium hydroxide and sodium chloride were purchased from Laurylab. PC-SA and PC-SK membranes were purchased from PC Cell $\mathrm{GmbH}$ German enterprise. The thickness of PC-SA and PC-SK commercial membranes in acidic and anionic form was about $120 \mu \mathrm{m}$ in the dry state and about $150 \mu \mathrm{m}$ in the wet state.

\section{2 | Membrane preparation}

$\mathrm{CINH} 2$ membrane was prepared by solvent casting evaporation, by a reaction between sulfochlorated polyethersulfone and aminated polyethersulfone (NH2-PES), following the procedure described in our previous work. ${ }^{19}$

Different rates of NH2-PES $(0.1,0.2,0.3,0.4$, and 0.6 equivalent $\mathrm{mol})$ have been tested to react with $\left(\mathrm{SO}_{2} \mathrm{Cl}\right)$ groups of sulfochlorated PES. Reducing the rate led to loose mechanical stability, as the results obtained with low rates of NH2-PES (0.1 equivalent in mol) show that the membrane always loses this mechanical stability at high temperature, but with high levels of crosslinking agent (eg, 0.4 and 0.6 equivalent mol of $\mathrm{NH} 2-\mathrm{PES}$ ), the resulting membrane gains stability in the water at high temperature but loses in terms of ionic conductivity. The best compromise has been obtained using 0.2 mol equivalents of $\mathrm{NH} 2$-PES reacted with sulfochlorated PES because, with this rate, the fragility and water swelling of the membrane are greatly reduced and the ionic conductivity was close to that of the commercial Nafion membrane. The crosslinking was confirmed by the insolubility of the membrane in the reaction solvent, dimethylacetamide.

\subsection{Characterization}

\subsection{1 | Contact angle}

Contact angle measurements (CA) were performed for $\mathrm{CINH} 2$ membrane sample. The sample was at least $1.5 \mathrm{~cm} \times 1.5 \mathrm{~cm}$ to avoid changes in the sample surface caused by swelling effect. The CA of $\mathrm{CINH} 2$ membrane was determined using a Theta optical tensiometer (Attention). Five microliter deionized water droplet was immobilized using a syringe on the sample membrane surface under ambient temperature. The wetting process was recorded until no significant change in the surface was observed anymore. A light source was placed behind the sample and CA was calculated with the help of a computer software. $^{29}$

\subsection{2 | Water uptake}

Membrane sample was first dried in a vacuum oven at $80^{\circ} \mathrm{C}$ for 2 days and then was accurately weighed to confirm its exact dry weight. The membrane was then immersed in deionized water for 2 days at room temperature. Measurements of water uptake at high temperature were realized after putting membrane in deionized water for 6 hours and wet weight of that membrane was recorded. Droplets of adsorbed water on the membrane surface were absorbed by hydrophilic tissue paper. From the difference in mass, before and after complete drying of the membrane, WR values were measured, ${ }^{30-32}$ as the relative weight gain per gram of dry sample using the following Equation (1):

$$
\mathrm{WR}=\frac{\mathrm{W}_{\mathrm{wet}}-\mathrm{W}_{\mathrm{dry}}}{\mathrm{W}_{\mathrm{dry}}} * 100,
$$

where $W_{\text {wet }}$ and $W_{\text {dry }}$ are the weights of the wet and dry membranes, respectively.

\subsection{3 | Proton transport number}

Cationic transport number was measured using a glass cell constituted by two symmetrical glass compartments called Hittorf Cell. Compartments were separated with $\mathrm{CINH} 2$ membrane and each compartment was filled with aqueous $\mathrm{H}_{2} \mathrm{SO}_{4}(1 \mathrm{M}, 50 \mathrm{~mL})$. CINH2 membrane in a disk form $\left(\mathrm{S}=4.15 \mathrm{~cm}^{2}\right)$ was motionlessly placed between them as described in Ref. 33. The calculation of proton transport number is explained in Ref. 18.

\subsubsection{Ionic conductivity}

The ionic conductivities of $\mathrm{CINH} 2$ and pristine membranes were measured as a function of temperature at $0 \%$ and $100 \%$ relative humidity by electrochemical impedance spectroscopy, using a Biologic Science 
Instruments VSP potentiostat. CINH2 and S-PES disk form samples were placed between two platinized blocking electrodes. Relative humidity $(\mathrm{RH})$ was controlled by using a stainless steel sealed-off cell consisting of two cylindrical compartments (hot and cold) connected by a tube and held at different temperatures. $\mathrm{RH}$ value was calculated from the ratio between the pressures of saturated water vapor at each temperature. Nyquist plots were recorded with a frequency response analysis (FRA) in interval frequency between $1000 \mathrm{kHz}$ and $10 \mathrm{~Hz}$ with oscillating voltage amplitude of $10 \mathrm{mV}$. Electrical resistance (R) was measured from the intercept of Nyquist plot at high frequency with the real horizontal axis. ${ }^{34}$ lonic conductivity $(\sigma, \mathrm{S} / \mathrm{cm})$ was calculated using the following equation:

$$
\sigma\left(\frac{m S}{c m}\right)=\frac{e}{R \times S}
$$

where $e$ denotes the thickness, $S$ denotes the surface of the membrane placed between the two electrodes, and $R$ denotes the electrical resistance.

\subsection{5 | Electrodialysis equipment}

Electrodialysis operation was carried out on a laboratory stack (PC Cell ED 64 002) supplied by PCA-Polymer Chemie Altmeier $\mathrm{GmbH}$ and PC Cell GmbH, Heusweiler, Germany. ED cell was composed of cation and anion exchange membranes, spacers, and two electrodes (anode and cathode) made of an alloy of Pt/Ir-coated titanium. Membranes and spacers were stacked between the two electrodes ends. Plastic separators were placed between cationic and anionic membranes to ensure the separation of flow paths of dilute and concentrated streams.

In this work, two stacks were used. The first one was equipped with two cation exchange membranes $(\mathrm{CINH} 2)$ and two anion exchange membranes (PC-SA). The second was equipped with 10 cation and anion membranes (CINH2 and PC-SA membranes, respectively). Information from a manufacturer of membranes is collected in Table 1 . The active surface for each membrane, anionic and cationic, was $64 \mathrm{~cm}^{2}$ and each tank (dilute, concentrate and rinsing) was equipped with $1 \mathrm{~L}$ of solution.

\section{Stack with two cation and anion membranes}

During all experiments, $1 \mathrm{~L}$ of $\mathrm{NaCl}$ solution was used for dilute and concentrate tanks. Two liters of sodium sulfate $\left(\mathrm{Na}_{2} \mathrm{SO}_{4}, 0.1 \mathrm{M}\right)$ was

TABLE 1 Ion exchange capacity of all membranes

\begin{tabular}{llll} 
Membrane & Surface & Thickness $(\mu \mathrm{m})$ & IEC \\
S-PES & $9 \mathrm{~cm}^{2}$ & $120 \pm 5$ & $2.60 \pm 0.05 \mathrm{meq} / \mathrm{g}$ \\
CINH2 & $9 \mathrm{~cm}^{2}$ & $120 \pm 5$ & $2.20 \pm 0.05 \mathrm{meq} / \mathrm{g}$ \\
\hline PC-SA & $9 \mathrm{~cm}^{2}$ & $130 \pm 5$ & $1.25 \pm 0.05 \mathrm{meq} / \mathrm{g}$ \\
PC-SK & $9 \mathrm{~cm}^{2}$ & $130 \pm 5$ & $1.30 \pm 0.05 \mathrm{meq} / \mathrm{g}$ \\
\hline
\end{tabular}

used as electrode rinse solution, which circulate in electrode compartments in order to prevent chlorine or hypochlorite generation. The flow rate of the electrode rinse for all experiments was $80 \mathrm{~L} / \mathrm{h}$. The same solution of $\mathrm{NaCl}$ for concentrate and dilute was used. Prior to the experiments, $\mathrm{pH}$ of all solutions was adjusted by addition of $\mathrm{HCl}$ and/or $\mathrm{NaOH}(1 \mathrm{M})$. However, the flow rate of dilute and concentrate tanks was fixed for all experiments to $10 \mathrm{~L} / \mathrm{h}$.

Conductivity measurements of dilute and concentrate compartments were made by imposing a potential ranging from 0 to $24 \mathrm{~V}$. A conductometer (712 Conductometer, Metrohm AG) was used to measure the conductivities of dilute and concentrate compartments. Water conductivity directly depends on its salt content. At the end of each experiment, a cleaning cycle of ED cell was performed by circulation of cleaning solutions, containing $\mathrm{HCl}(0.1 \mathrm{M}), \mathrm{NaOH}(0.1 \mathrm{M})$, and distilled water, for $30 \mathrm{mn}$ to remove any deposits.

\section{Stack with 10 cation and anion membranes}

The flow rate of all solutions was fixed at $80 \mathrm{~L} / \mathrm{h}$ for all experiments. Before starting the electrodialysis test, aqueous solutions of $\mathrm{NaCl}$ were pumped in dilute and concentrate compartments (with 3 and $5 \mathrm{~g} / \mathrm{L} \mathrm{NaCl}$ solutions). Ionic conductivity in the dilute reservoir was measured according to the constant applied voltage (10 V) until it reaches about $0.5 \mathrm{mS} / \mathrm{cm}$. During ED tests, in batch recirculation mode, the conductivity was measured using a Consort D292 conductivity meter equipped with a D292 conductivity cell. Prior experiments, the conductivity cell was calibrated at room temperature.

In electrodialysis measurement, a stack with 10 cationic and anionic membrane systems are generally considered as the best option, as the interfacial resistance is reduced and polarization are not measured. The drawback of the assemblies with 10 anion PC-SA and cation $\mathrm{CINH} 2$ membranes is that the cost of commercialized and synthesized membranes. However, this system can be used when applying a potential to the system, although a current can be imposed over this assembly (as in the choice of the assemblies system in this work). When dilute and concentrate conductivities signals are measured, the current can be recorded.

ED configuration consists of a DC generator, a concentrate tank, a dilute tank, a rinsing electrode tank, and three pumps, each equipped with a flow-meter (PC Cell $\mathrm{GmbH}$ ). Electrodes were placed in two polypropylene blocks. The membranes and spacers are stacked between electrodes forming 10 repeating sections from the ED stack. A cell pair consists of the following: (cation exchange membrane $\left(\mathrm{CINH} 2, \mathrm{~S}=64 \mathrm{~cm}^{2}\right)$, dilute flow spacer $(0.5 \mathrm{~mm})$, anion exchange membrane (PC-SA, $S=64 \mathrm{~cm}^{2}$ ), concentrate flow spacer. Plastic spacers and ion membranes are placed in the stack repeatedly in sandwich form to form the flow paths of the dilute and concentrate streams, which circulates separately.

\subsection{Data analysis}

The experiments aimed to study the effects of voltage, current, and concentration of solutions on batch circulation mode in ED cell 
performance using the newly synthesized $\mathrm{CINH} 2$ membrane. All figures and tables refer to changes in concentration in the dilute solution. Firstly, we present the ED performances according to the potential using the stack with two $\mathrm{CINH} 2$ and two PC-SA membranes. Secondly, we present the results as a function of time using a stack with $10 \mathrm{CINH} 2$ and PC-SA membranes.

\subsubsection{Determination of the limiting current}

The limiting current density (LCD) is a paramount parameter for the characterization of transport rates in electrochemical systems as electrodialysis process, which is the area of interest in this work. When an electrochemical system functions under limiting current, the reactions operate at the maximum rate, facilitating comparison with other electrochemical systems. It is known that an electrodialysis process indicates higher electrical resistance when used above LCD, which causes difficulties such as water dissociation or salt precipitation. It is, therefore, necessary to determine the LCD to avoid problems and to operate successfully, the electrodialyzer. ${ }^{35,36}$ Limiting current can be experimentally determined by reporting the electrical resistance value in the membrane stack $(E / I)$ related to the reciprocal electric current $(1 / \mathrm{l})$. This is called a Cowan Brown plot. ${ }^{37}$ Usually, limiting current depends on solutions, membranes properties, stack construction, and flow velocity (flow rate).

\subsection{2 | Demineralization rate}

Determination of demineralization rate (DR) in this study can be determined as follows ${ }^{38}$ :

$$
D R(\%)=100 *\left(1-\frac{C_{t}^{D}}{C_{0}}\right),
$$

where the demineralization rate expressed in percentage, $C_{t}^{D}$ and $C_{0}$ are, respectively, the initial and end conductivity of the dilute expressed in $\mathrm{S} / \mathrm{cm}$.

\subsection{3 | lonic transport flux}

The ionic transport flux was evaluated to compare it with the ions transport from the feed phase to the receiver phase. The flux (J) was determined by using the following equation:

$$
\mathrm{J}\left(\mathrm{mol} \cdot \mathrm{cm}^{-2} \cdot \mathrm{s}^{-1}\right)=\left(\frac{V}{A}\right)\left(\frac{\Delta C}{\Delta t}\right)
$$

where $V$ is the volume of receive phase (L), $A$ is the effective membrane area $\left(\mathrm{cm}^{2}\right), \Delta C$ is the transported amount of ions at a time $(\mathrm{mol} / \mathrm{L})$, and $\Delta t$ is the period time (s).

\subsection{4 | Specific power consumption}

Specific power consumption (SPC) is the required energy to treat a one unit volume of solution. SPC is calculated using the following equation:

$$
\operatorname{SPC}\left(\mathrm{W} \cdot \mathrm{h} \cdot \mathrm{L}^{-1}\right)=\frac{E \cdot \int_{0}^{t} I(t) d t}{V}
$$

where $E$ is the applied potential, $I$ is the current, $V$ is the dilute stream volume, and $t$ is the time.

\section{3 | RESULTS AND DISCUSSION}

\subsection{Water uptake}

The variations in the water uptake of the organically modified membrane by chemical crosslinking compared with that of the sulfonated polyethersulfone $\left(1.3 \mathrm{H}^{+} \mathrm{pmu}\right)$ have been shown in Figure 1 as a function of temperature. It is observed that $\mathrm{CINH} 2$ membrane has the tendency to absorb less water than pristine S-PES (1.3 $\mathrm{H}^{+}$pmu) membrane sample over the entire temperature range between room temperature and $100^{\circ} \mathrm{C}$.

These results prove that the chemical crosslinking agent (NH2-PES) plays a dominant role in decreasing the water uptake rate of $\mathrm{CINH} 2$ membrane. For example, the percentages of water uptake at room temperature, presented in Figure 1, for S-PES $\left(1.3 \mathrm{H}^{+} \mathrm{pmu}\right)$ (without $\mathrm{NH} 2-\mathrm{PES})$ and $\mathrm{CINH} 2\left(1.1 \mathrm{H}^{+}\right.$pmu) (with $\left.\mathrm{NH} 2-\mathrm{PES}\right)$ membranes are 83 and 23 (wt. \% water/wt. membrane), respectively.

The decrease in water uptake rate can be attributed to the creation of the crosslinking bridges created by covalent bond occurring between $\mathrm{SO}_{2} \mathrm{Cl}$ and $\mathrm{NH}_{2}$ groups in the organic $\mathrm{CINH} 2$ membrane.

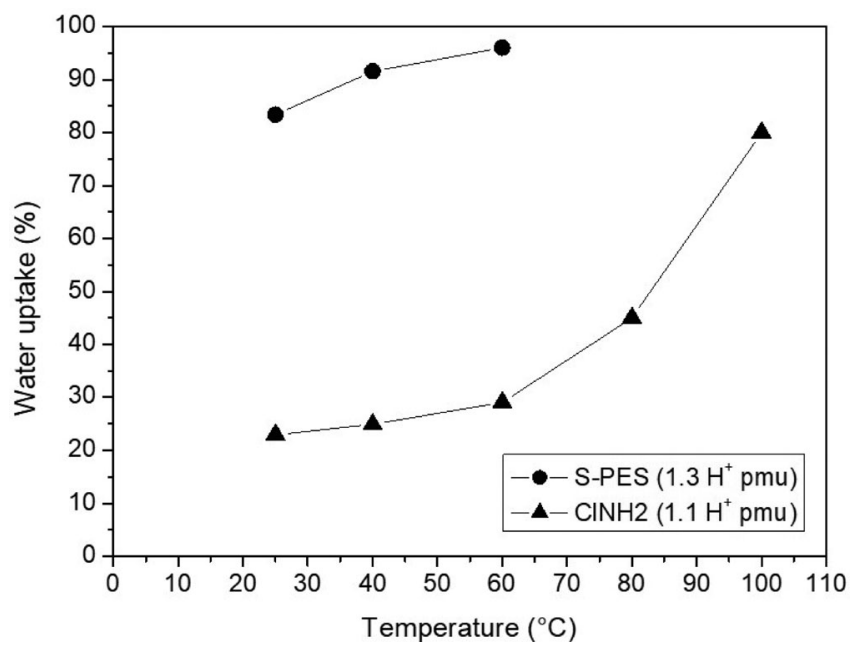

FIGURE 1 Water uptake according to the temperature of $\mathrm{CINH} 2$ and pristine membranes 
Figure 1 shows that the water uptake of $\mathrm{CINH} 2$ membrane remains stable between room temperature and $60^{\circ} \mathrm{C}$, the temperature at which pristine S-PES membrane dissolves completely. This dissolution might be due to high water affinity of the S-PES $\left(1.3 \mathrm{H}^{+} \mathrm{pmu}\right)$ membrane with a high sulfonation rate. Then, the water uptake for $\mathrm{CINH} 2$ membrane increases depending on the temperature, and reaches $80 \%$ at $100^{\circ} \mathrm{C}$. In boiling distilled water, the membrane keeps its dimensional mechanical stability. The chemical crosslinking of the S-PES membrane increases, thus its mechanical stability in water, and reduces its water uptake.

\section{2 | Contact angle}

Contact angle measurements allow investigating one of the most important measurable characteristics to describe the IEM performances and fouling phenomena, such as surface hydrophobicity that plays a critical role in ions transfer. The contact angle of $\mathrm{CINH} 2$ and virgin membranes was measured as shown in Figure 2 , and its value is about $67^{\circ}$ and $51^{\circ}$, respectively. These high angles indicate that flat sheet $\mathrm{CINH} 2$ and S-PES membranes present a good hydrophilic character. The virgin membrane has a higher contact angle than that of the crosslinked membrane, which is due to the high sulfonation rate of the non-crosslinked membrane. This result is in agreement with the water uptake measurement.

\section{3 | lonic intrinsic conductivity}

Figure 3 compares the intrinsic conductivity values of protons as a function of temperature of S-PES and $\mathrm{CINH} 2$ membranes, at $0 \%$ and $100 \%$ relative humidity. As revealed by the curves, the conductivity of the $\mathrm{CINH} 2\left(1.1 \mathrm{H}^{+}\right.$pmu) membrane is higher than the unmodified membrane over the whole temperature range (between ambient temperature ant $120^{\circ} \mathrm{C}$ ) with and without relative humidity.
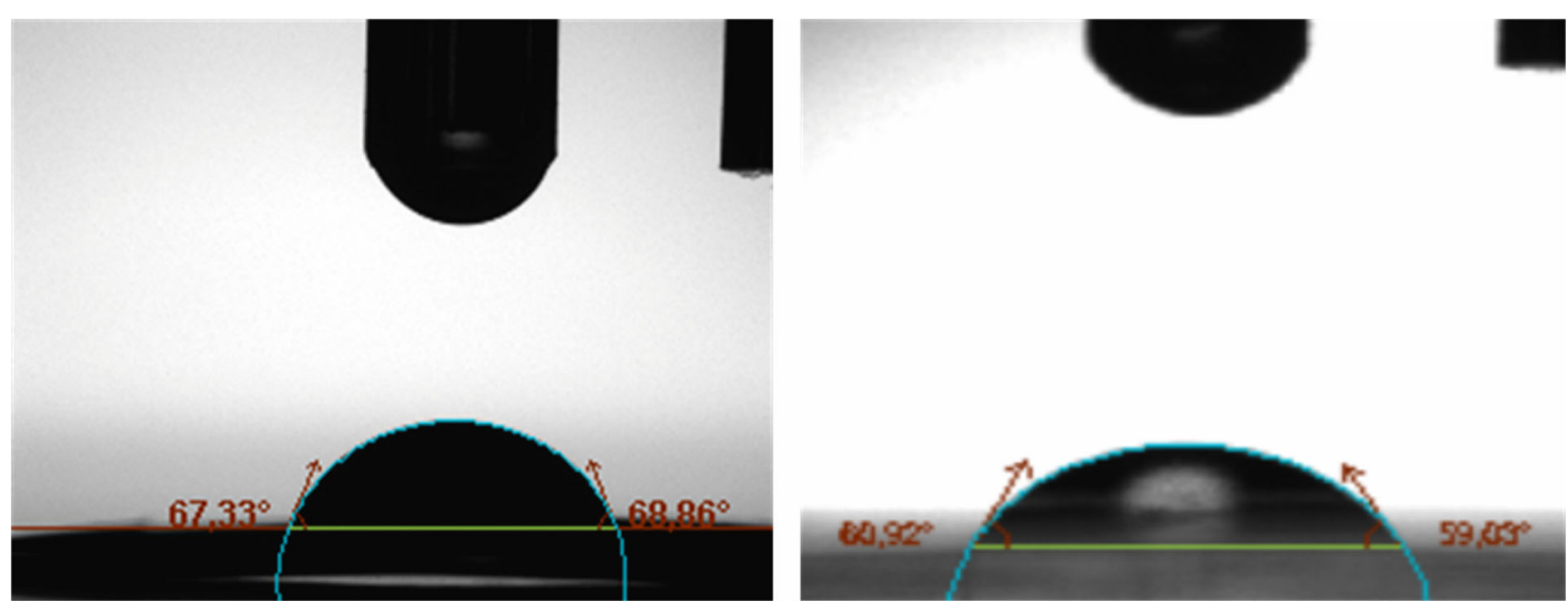

At $0 \%$ relative humidity, the conductivity of both membranes reaches a maximum at about $60^{\circ} \mathrm{C}$ to $70^{\circ} \mathrm{C}(40 \mathrm{mS} / \mathrm{cm}$ for $\mathrm{CINH} 2$ and $25 \mathrm{mS} / \mathrm{cm}$ for S-PES). Above this temperature, the conductivity drops because of water evaporation.

Even if the S-PES membrane dissolves completely in $60^{\circ} \mathrm{C}$ liquid water (Figure 1), it is mechanically stable in water vapor of $100 \%$ relative humidity, and the conductivity measurement at $100 \% \mathrm{RH}$ was possible. The virgin membrane exhibits similar behavior with and without humidification between the room temperature and $80^{\circ} \mathrm{C}$, then reaches a peak value above $100^{\circ} \mathrm{C}$. This behavior can be explained by the solvation of sulfonic groups (1.3 proton per monomer unit) by vapor water, which reaches a maximal value of $57 \mathrm{mS} / \mathrm{cm}$ at $100^{\circ} \mathrm{C}$.

Although the IEC of S-PES is higher than that of $\mathrm{CINH}$, the ionic conductivities of $\mathrm{CINH} 2$ membrane are greater than those of S-PES in the entire temperature range when relative humidity is $100 \%$. The ionic conductivity of $\mathrm{CINH} 2$ membrane increases first gradually between room temperature and $80^{\circ} \mathrm{C}$ and then more sharply, before

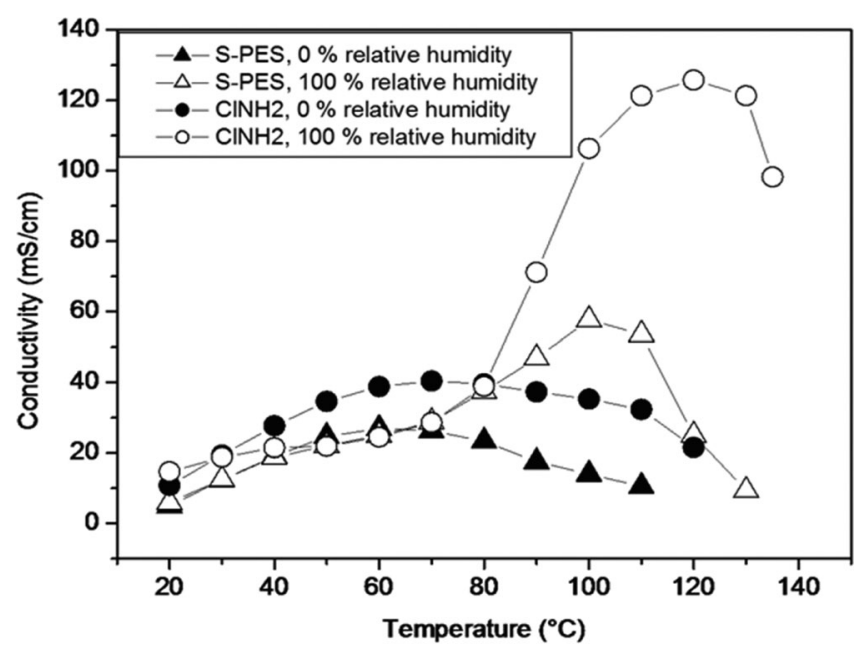

FIGURE 3 Comparison between proton intrinsic conductivity of $\mathrm{S}$-PES and $\mathrm{CINH} 2$ membranes

FIGURE 2 Contact angle of $\mathrm{CINH} 2$ and S-PES membranes 
reaching a peak value at $120^{\circ} \mathrm{C}$ of $125 \mathrm{mS} / \mathrm{cm}$. The higher proton conductivity of the $\mathrm{CINH} 2$ crosslinked membrane at high temperatures (around $120^{\circ} \mathrm{C}$ ) could be related to their higher water retention. A decrease of the conductivity after $120^{\circ} \mathrm{C}$ is eventually observed and is probably due to water evaporation. The conductivity of $\mathrm{CINH} 2$ membrane increases more rapidly with $100 \%$ relative humidity than S-PES. We notice that the temperature at which the $\mathrm{CINH} 2$ conductivity increases exponentially corresponds to the temperature at which the conductivity at $0 \% \mathrm{RH}$ decreases (around $70^{\circ} \mathrm{C}$ ).

A possible explanation of the difference of conductivities between $\mathrm{CINH} 2$ and S-PES is that crosslinking increases the proton conductivity and the stability in the water at high temperature of the polymer electrolyte (Figure 1). Moreover, these results (at $100 \% \mathrm{RH}$ ) clearly indicate that the presence of water enhances proton conductivity. These results are rather encouraging because they seem to indicate that the ionic conductivity process promotes molecular water absorption and favors the proton conduction pathways.

\subsection{Proton transport number}

Proton transport numbers, reported in Table 2, were measured for two membranes (S-PES and $\mathrm{CINH} 2$ ) as a function of current density and $\mathrm{H}_{2} \mathrm{SO}_{4}$ solution concentration. $\mathrm{CINH} 2$ membrane $\left(1.1 \mathrm{H}^{+}\right.$pmu) possesses a higher transport number (0.99) than the pristine membrane, which is unexpected, considering the higher hydrophilicity of the pristine membrane. This can be explained by the presence of a favorable rearrangement of the chemical structure skeleton of $\mathrm{CINH} 2$ membrane after chemical crosslinking, which is confirmed by the water uptake and ionic conductivity results. Consequently, these results indicate that the synthesized membrane has higher capacity toward the cation ion compared to pristine membrane. All the values of transport numbers measured for S-PES and $\mathrm{CINH} 2$ membranes were between 0.9 and 1 . The membranes are selectively protonconducting whether crosslinked or non-crosslinked.

\section{5 | lonic exchange capacity}

Ionic exchange capacity values of different membranes are reported in Table 1. For $\mathrm{CINH} 2$ membrane $\left(1.1 \mathrm{H}^{+}\right.$pmu), 0.2 equivalent in mol of aminated polyethersulfone has been reacted with pristine sulfochlorated polyether sulfone (Cl-PES), leaving $1.1 \mathrm{SO}_{2} \mathrm{Cl} \mathrm{pmu}$ unreacted and further hydrolyzed to $1.1 \mathrm{SO}_{3} \mathrm{H}$ group pmu as titrated. The results, given in Table 1, show that the non-crosslinked membrane gives the maximal ion exchange capacity $(2.6 \mathrm{meq} / \mathrm{g})$, and that the creation of crosslinking bridge in $\mathrm{CINH} 2$ membrane leads to a decrease of the ionic exchange capacity. Despite the decrease of IEC and water uptake for $\mathrm{CINH} 2$ membrane, the ionic conductivity and transport number are improved.

\section{4 | DESALINATION PERFORMANCE OF THE FABRICATED MEMBRANES}

\subsection{Effect of applied voltage on $\mathrm{NaCl}$ removal with two membrane assembly}

After its complete characterization, $\mathrm{CINH} 2$ membrane was employed in electrodialytic removal of $\mathrm{NaCl}$ from aqueous solution to evaluate its performance during electrodialysis at room temperature. The desalination results were compared with those obtained with a commercial membrane PC-SK (German PC Cell GmbH society).

The results of limiting current and debiting current of the $\mathrm{CINH} 2$ / PC-SA assembly and PC-SK/PC-SA commercial assembly are presented in Table 3. We observe that the limiting current increases with

TAB LE 3 Limiting and debited current in different assemblies

\begin{tabular}{lll}
\hline Different assemblies & Limit current (A) & Debited current (A) \\
\hline $\begin{array}{l}\mathrm{CINH} 2 / \mathrm{PC}-\mathrm{SA} \text { assembly } \\
0.5 \mathrm{~g} / \mathrm{L} \text { of } \mathrm{NaCl}\end{array}$ & 0.40 & 0.32 \\
$\begin{array}{l}\mathrm{CINH} 2 / \mathrm{PC}-\mathrm{SA} \text { assembly } \\
1.5 \mathrm{~g} / \mathrm{L} \text { of } \mathrm{NaCl}\end{array}$ & 0.71 & 0.57 \\
$\mathrm{CINH} 2 / \mathrm{PC}-\mathrm{SA}$ assembly & 1.00 & 0.80 \\
$3.0 \mathrm{~g} / \mathrm{L}$ of $\mathrm{NaCl}$ & & 0.27 \\
$\mathrm{PC}-\mathrm{SK} / \mathrm{PC}-\mathrm{SA}$ assembly & 0.34 & \\
$0.5 \mathrm{~g} / \mathrm{L}$ of $\mathrm{NaCl}$ & & 0.78 \\
\hline $\mathrm{PC}-\mathrm{SK} / \mathrm{PC}-\mathrm{SA}$ assembly & 0.98 & \\
$1.5 \mathrm{~g} / \mathrm{L}$ of $\mathrm{NaCl}$ & & 0.96 \\
$\mathrm{PC}-\mathrm{SK} / \mathrm{PC}-\mathrm{SA}$ assembly & 1.20 & \\
$3.0 \mathrm{~g} / \mathrm{L}$ of $\mathrm{NaCl}$ & &
\end{tabular}

TABLE 2 Comparison between transport numbers of $\mathrm{CINH} 2$ and pristine membrane

\begin{tabular}{|c|c|c|c|c|c|c|}
\hline Membrane & Surface & {$\left[\mathrm{H}_{2} \mathrm{SO}_{4}\right]$} & $\begin{array}{l}\text { Current } \\
\text { intensity } \\
(\mathrm{mA})\end{array}$ & $\begin{array}{l}\text { Time } \\
\text { (min) }\end{array}$ & $\begin{array}{l}\mathbf{t}^{+} \\
\text {cathodic }\end{array}$ & $\begin{array}{l}\mathbf{t}^{+} \\
\text {anodic }\end{array}$ \\
\hline CINH2 $\left(1.1 \mathrm{H}^{+} \mathrm{pmu}\right)$ & $4.15 \mathrm{~cm}^{2}$ & $1 \mathrm{M}$ & 100 & 188 & 0.99 & 0.99 \\
\hline CINH2 $\left(1.1 \mathrm{H}^{+} \mathrm{pmu}\right)$ & $4.15 \mathrm{~cm}^{2}$ & $1 \mathrm{M}$ & 70 & 243 & 0.99 & 0.99 \\
\hline CINH2 (1.1 $\left.\mathrm{H}^{+} \mathrm{pmu}\right)$ & $4.15 \mathrm{~cm}^{2}$ & $1 \mathrm{M}$ & 40 & 430 & 0.99 & 0.99 \\
\hline S-PES (1.3 $\left.\mathrm{H}^{+} \mathrm{pmu}\right)$ & $4.15 \mathrm{~cm}^{2}$ & $1 \mathrm{M}$ & 100 & 188 & 0.98 & 0.99 \\
\hline S-PES (1.3 $\left.\mathrm{H}^{+} \mathrm{pmu}\right)$ & $4.15 \mathrm{~cm}^{2}$ & $1 \mathrm{M}$ & 70 & 243 & 0.99 & 0.98 \\
\hline S-PES $\left(1.3 \mathrm{H}^{+} \mathrm{pmu}\right)$ & $4.15 \mathrm{~cm}^{2}$ & $1 \mathrm{M}$ & 40 & 430 & 0.98 & 0.97 \\
\hline
\end{tabular}


$\mathrm{NaCl}$ concentration. A slight difference has been observed between the limiting currents of the two assemblies.

Figures 4-7 represent the effect of the initial feed solution concentration on ED performances as a function of the applied voltage, using two elaborated $\mathrm{CINH} 2$ membranes and two commercial PC-SA membranes.

The change in $\mathrm{NaCl}$ conductivity in dilute and concentrated tanks for both membranes (fabricated and commercial) are shown in Figure 4 as a function of the applied voltage. The conductivity in the dilute tank is found to decrease, whereas it increases in the concentrated tank according to the desalination for both assemblies. The conductivity of the dilute solution tank results from the permeation of anion and cation in the AEM and CEM under the applied electric field, resulting in a decrease of ions concentration in the dilute tank. This is

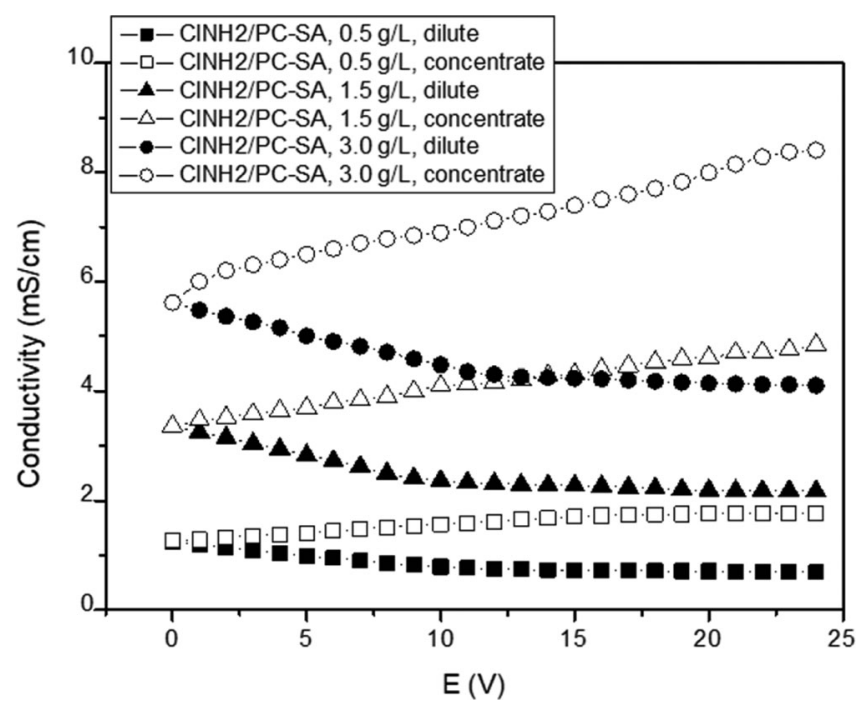

FIGURE 4 The conductivity change of $\mathrm{NaCl}$ curves with different assemblies containing two ionic membranes

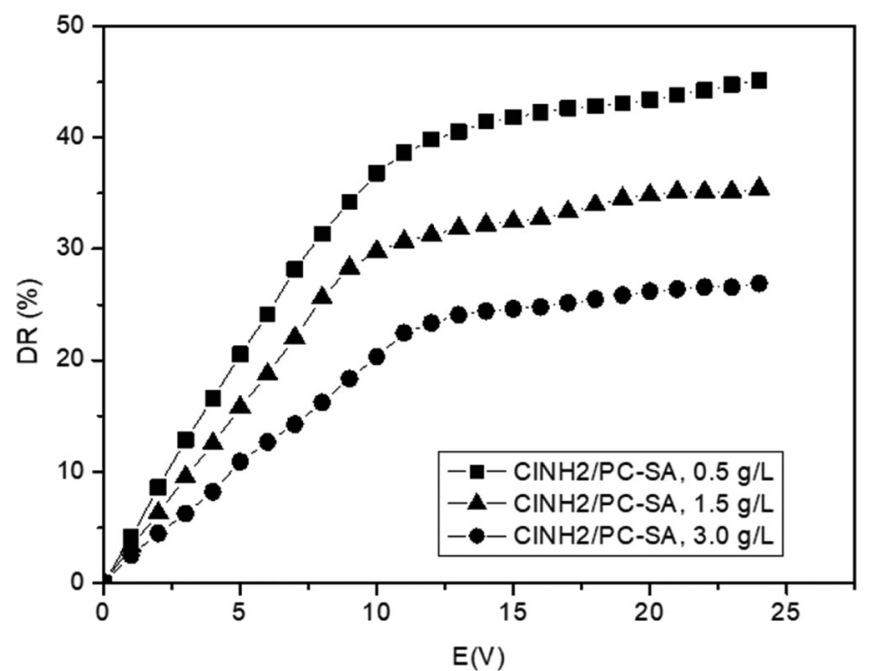

FIGURE 5 Demineralization rate curves of $\mathrm{CINH} 2 / \mathrm{PC}-\mathrm{SA}$ assembly associated with ion exchange in the membrane. ${ }^{39}$ The membrane, $\mathrm{CINH} 2(1.1 \mathrm{H}+$ pmu), used in electrodialysis removal of $\mathrm{NaCl}$ from aqueous solution shows better desalination performance than the commercial membrane PC-SK. CINH2 (1.1 H+ pmu), as found by Mourad ben Ski Ali and All. ${ }^{38}$ It can be explained by cations migrating more rapidly from dilute cell to concentrated one, due to higher IEC and lower area resistance in synthetized $\mathrm{CINH} 2$ membrane.

Generally, below limiting current, increasing the amount of applied voltage increases the removal of ions. This effect is distinctly shown for ions in Figure 5. In order to show this effect, experiments were conducted. The demineralization rate (DR) was calculated using Equation (3). Then, the DR was plotted vs the applied voltage to the stack.

Demineralization rates are dependent on the concentration of feed solution (Figure 5). Effectively, when increasing the concentration, DR decreases. As it is already known, DR calculation depends on

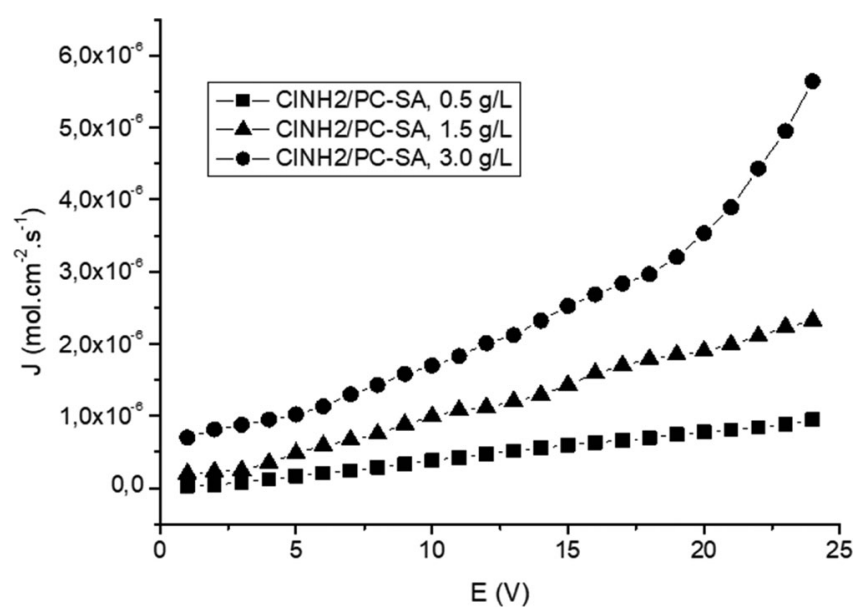

FIGURE 6 Ionic flux curves of CINH2/PC-SA assembly

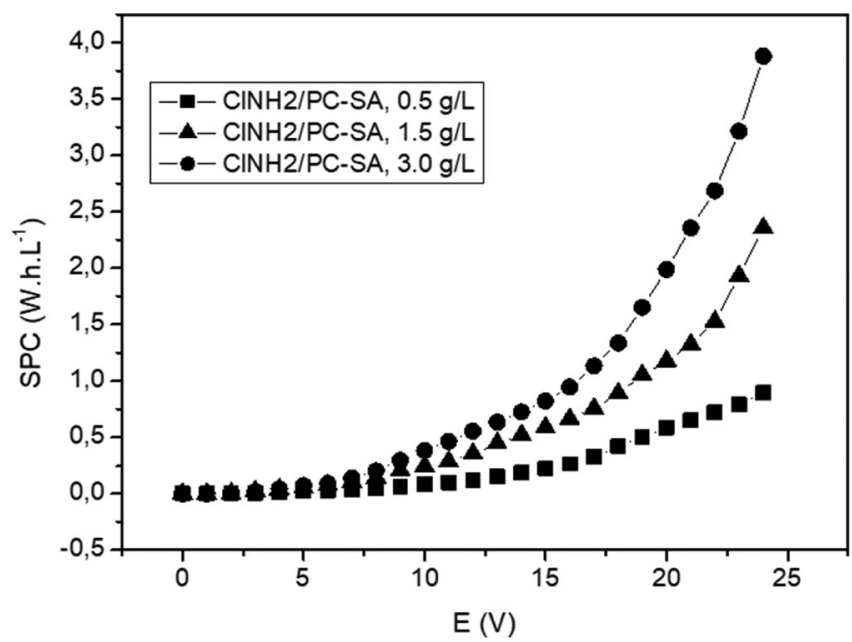

FIGURE 7 Specific power consumption curves of CINH2/PC-SA assembly 
the concentration and the amount of transported ions. Therefore, DR evolves in inverse proportion to concentration.

We notice in Figure 5 that DR increases as the applied voltage is increased for all curves with different concentrations. There are two distinguished parts in these curves. In the first part, the curve displays an almost linear increase of DR vs voltage between 0 and $10 \mathrm{~V}$. In the same region, Figure 7 shows that SPC is almost quasi-constant. In the second part, DR increases continuously but not significantly.

All the curves of ionic flux $(J)$ and energy consumption (SPC) have a similar increasing appearance over the entire range of applied voltage. As depicted in Figures 6 and 7, J and SPC through the membranes assembly are low for the lowest initial feed concentration according to the applied voltage. At these conditions, it is noted that SPC presents low values between 0 and $5 \mathrm{~V}$. Then, SPC increases due to the activation polarization.

It was not possible to increase the initial feed concentration more than $3 \mathrm{~g} / \mathrm{L}$ because of the overheating of the cell. It is, therefore, suitable to use this ED process with a stack containing more exchange membranes, which is the scope of the second part of this work.

\section{2 | Effect of circulation mode on $\mathrm{NaCl}$ removal with 10 membrane assembly}

The suitability of the developed membranes for electromembrane applications was assessed in a custom-designed ED cell, containing 10 ion exchange membranes, in terms of conductivity, demineralization rate, concentration evolution, ionic flux, and energy consumption, for the salt removal experimental condition and compared. ED experiments were realized in a batch recirculation mode and were conducted by pumping feed solutions ( 3 and $5 \mathrm{~g} / \mathrm{L} \mathrm{NaCl}$ ) into the dilute tank with a flow rate of $80 \mathrm{~mL} / \mathrm{mn}$ and applied voltage of $10 \mathrm{~V}$.

Figures 8-13 show the results obtained for the experiment on batch recirculation mode for 3 and $5 \mathrm{~g} / \mathrm{L}$ initial feed concentrations. We noticed that DR is superior to $90 \%$ in all cases and the ionic transport decreases with experiment time. This is due to the salt exhaustion of the feed solution. We have notified also that the SPC amount increased linearly for all stacks by increasing the experiment time. In continuous mode, the results obtained from DR do not exceed 50 , while in batch recirculation mode we obtain better DR. However, more specific power was consumed.

It is clear from Figure 8 that $\mathrm{CINH} 2$ membranes show a decrease in conductivity with time compared to the commercial membrane, which may be due to the high ion exchange content in the membrane matrix and the rapid ions migration. Moreover, the recorded current over the stack presents two parts for the commercial and elaborated membrane. In the first part, the current for the synthesis membrane is higher than the commercial membrane. In the second part, the current for the $\mathrm{CINH} 2$ membrane is lower than the other PC-SK membrane investigated, as shown in Figure 9. This current alternation can be explained by several phenomena such as activation polarization, membrane resistance, concentration polarization, etc.

Figure 10 shows the variation of $\mathrm{NaCl}$ concentration in the diluting compartment as a function of time. The concentration of $\mathrm{NaCl}$

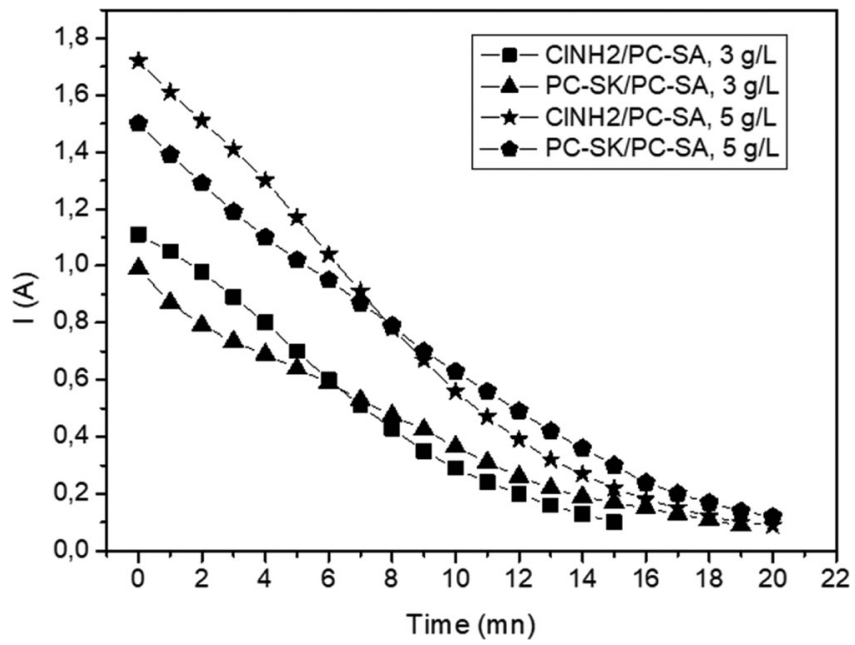

FIGURE 9 Evolution of current according to the time
FIGURE 8 Conductivity curves of different assemblies using synthetized and commercial membranes

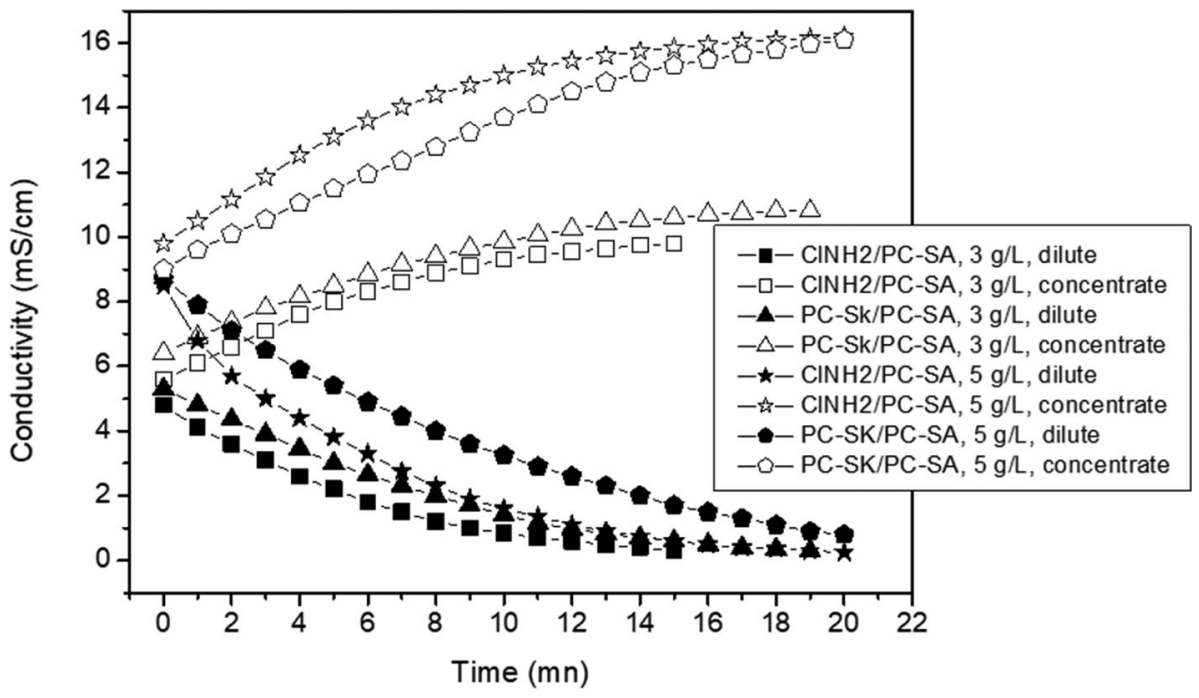




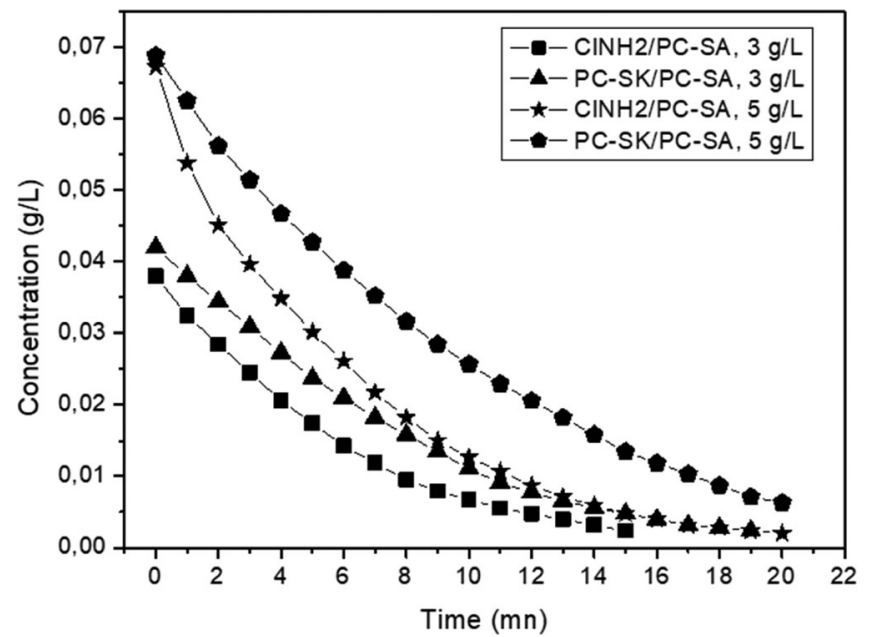

FIGURE 10 Concentration profiles of sodium chloride ions in different dilutes as a function of time

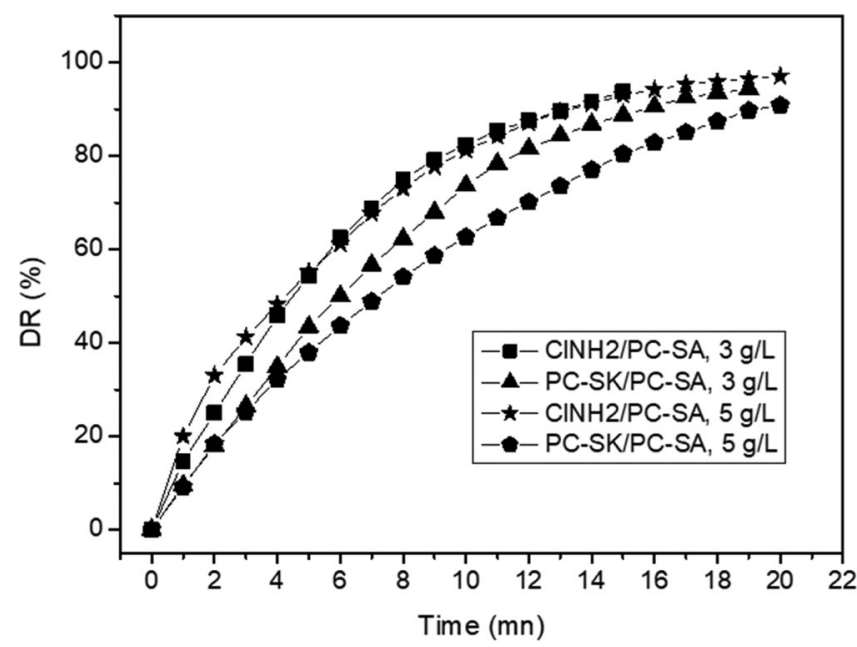

FIGURE 11 The required demineralization rate in the electrodialysis unit as a function of time by the synthetized and commercial membranes

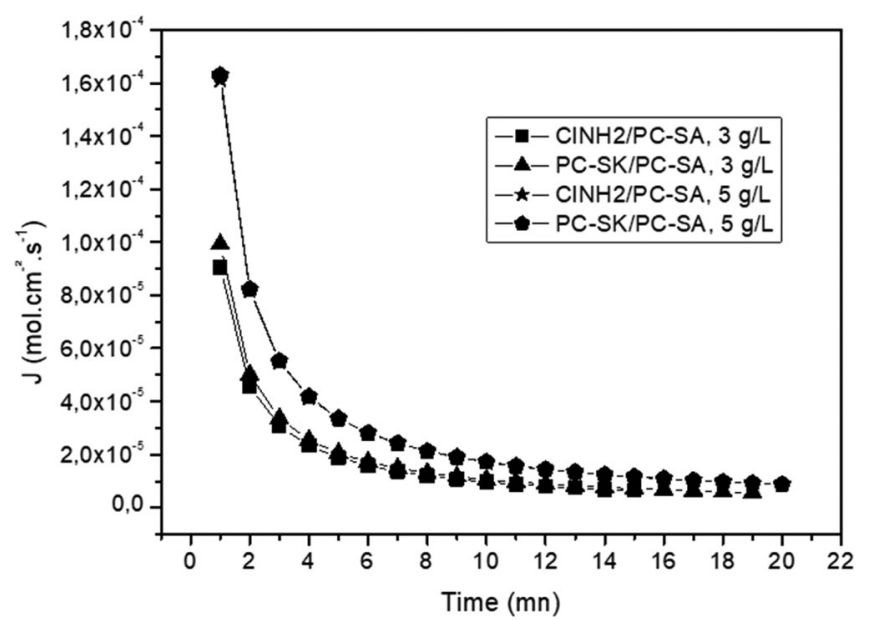

FIGURE 12 Ionic flux as a function of time using $\mathrm{CINH} 2$ and commercial membranes

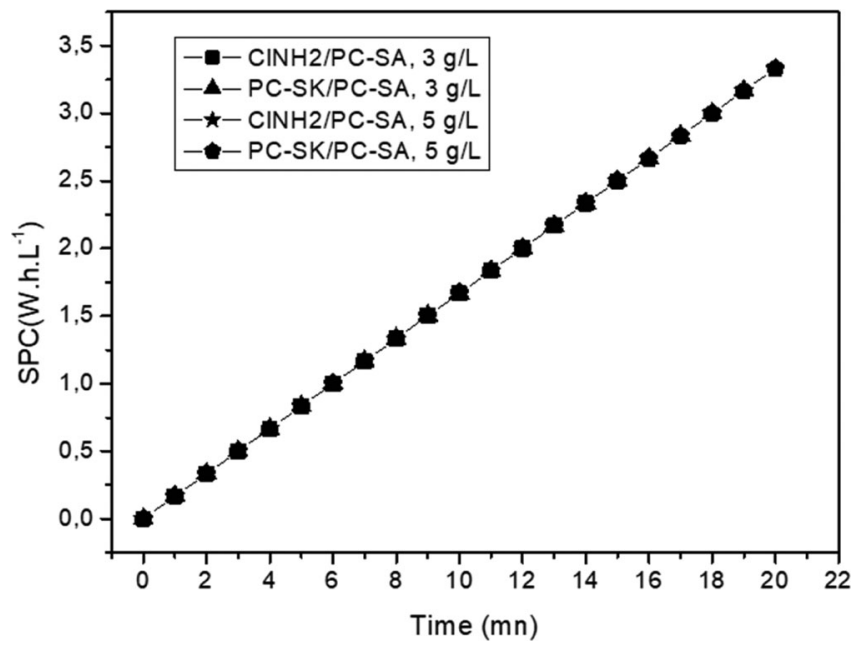

FIGURE 13 Desalination energy requirement as a function of time in the dilute compartments of 3 and $5 \mathrm{~g} / \mathrm{L} \mathrm{NaCl}$ solution at $298 \mathrm{~K}$

solution decreases with the increase of desalination time and is almost as low as with the commercial assembly. Desalination by electrodialysis was more efficient and faster than the commercial assembly, especially with $3 \mathrm{~g} / \mathrm{L}$ of feed solution. With the commercial assembly, the desalination time was 20 minutes. From both Figures 8 and 10, it is seen that the operation time needed for reaching $0.5 \mathrm{mS} / \mathrm{cm}$ becomes shorter using elaborated $\mathrm{CINH} 2$ membrane ( $15 \mathrm{mn}$ ).

Table 4 summarizes the desalination performances of prepared $\mathrm{CINH} 2$ membrane and commercial PC-SK membrane. The results confirm that, under the same experimental conditions, the values of demineralization rate, ionic flux of salts, and the energy consumption for prepared $\mathrm{CINH} 2$ membrane present better ED performance over those of commercial membrane due to the dense morphology of fabricated $\mathrm{CINH} 2$ membrane and to their good mechanical properties. ${ }^{22}$ Therefore, it could be preferably used for salt removal from water.

Figure 11 shows the demineralization rate evolution of the global system according to the time for different assemblies. With increasing time, the demineralization rate initially increased rapidly between 0 and 12 minutes, and the increase was less important when the time was higher than the 12 minutes for feed solutions of 3 and $5 \mathrm{~g} / \mathrm{L}$, respectively. The ED system used with commercial membranes showed the lowest demineralization rate. A higher demineralization rate could be achieved by increasing the time almost $100 \%$, although the ionic flux decreased accordingly.

The dependence of the ionic flux $(J)$ on the demineralization rate (DR) for the two stack ED system, using two different feed solutions, is shown in Figure 12. The ionic flux was relatively low and decreased highly with the demineralization rate when it was lower at $40 \%$ between 0 and 5 minutes for ED systems with feed solution 3 and $5 \mathrm{~g} / \mathrm{L}$, respectively. When the DR approaches high values (almost $100 \%$ ), the ionic flux decreases horizontally and approaches zero values.

Because the objective of this study is to obtain drinking water from brackish water, the conductivity of the dilute stream should be 
TABLE 4 The membrane electrodialysis (ED) performance compared to the commercial membrane PC-SK

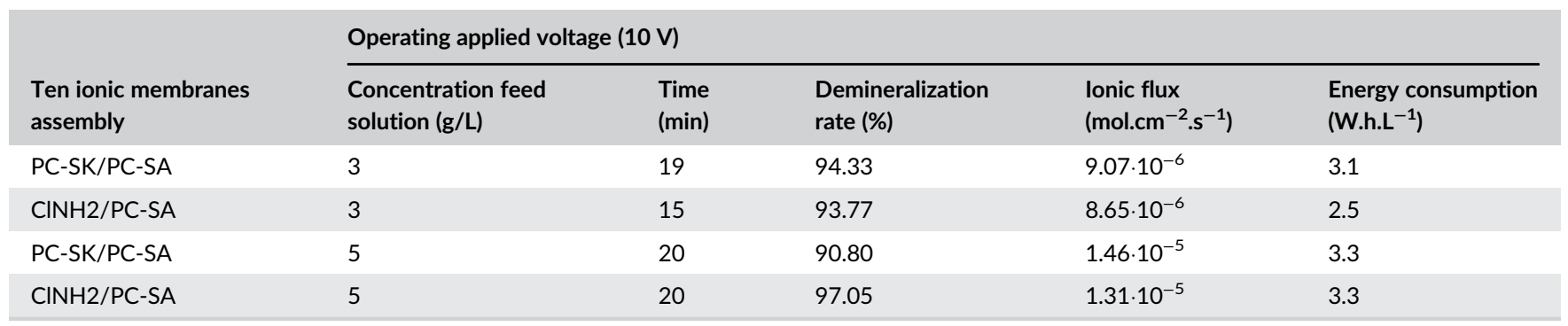

lower than $0.5 \mathrm{mS} / \mathrm{cm}$ according to the standard for drinking water quality in Tunisia and Europe. ${ }^{40,41}$ Therefore, the conductivity of the dilute stream using the selected $\mathrm{CINH} 2$ membrane could reach 0.3 $\mathrm{mS} / \mathrm{cm}$ after 15 minutes, and demineralization rates were approximately $100 \%$ for feed solutions of 3 and $5 \mathrm{~g} / \mathrm{L}$.

During demineralization, the energy consumption of the dilute solutions increased linearly according to the desalination time with 10 ionic membranes assembly. The results obtained for the SPCs with the synthesized and commercial membranes were similar. In Figure 13, no difference is observed and the curves superimposed, whereas a significant difference in SPC has appeared with two ionic membranes assembly (Figure 7).

Therefore, taking into account all these results, $\mathrm{CINH} 2$ membrane can be successfully applied for salt removal from water. The $\mathrm{CINH} 2$ / PC-SA assembly showed better desalination performance over the commercial assembly.

\section{5 | CONCLUSION}

Cation exchange membrane, newly synthesized by an easy chemical crosslinking method of sulfonated polyether sulfone $\left(1.3 \mathrm{H}^{+} \mathrm{pmu}\right)$ with aminated polyether sulfone NH2-PES, has been used for desalination via electrodialysis. The hydrophilic character of the $\mathrm{CINH} 2$ membrane is confirmed by contact angle measurement. The prepared membrane has higher stability at elevated temperatures in water. In addition, the water uptake in water aqueous solution was gradually decreased compared to the pristine membrane as the temperature was increased. The mechanical stability properties of $\mathrm{CINH} 2$ membrane were improved and the hydrophilic character was reduced. In particular, chemical crosslinking prevented the dissolution of $\mathrm{CINH} 2$ membrane in water at $60^{\circ} \mathrm{C}$. $\mathrm{CINH} 2$ membrane has ion exchange capacity of $2.2 \mathrm{meq} / \mathrm{g}(1.1 \mathrm{H}+\mathrm{pmu})$ and cation transport number close to unity. It was found that the membrane fixed ion concentration and water uptake were decreased after chemical crosslinked.

The fabricated $\mathrm{CINH} 2$ membrane showed excellent performance in the removal of $\mathrm{NaCl}$ from water in $\mathrm{ED}$ desalination applications. $\mathrm{ED}$ results revealed that the demineralization rate was increased using the new membrane and can reach $100 \%$. The obtained results are valuable in electromembrane processes, especially in the electrodialysis process related to water recovery and treatment. This showed that the $\mathrm{CINH} 2$ membranes could be successfully employed for desalination by electrodialysis in laboratory cell. The CINH2 $\left(1.1 \mathrm{H}^{+}\right.$ pmu) membrane showed higher desalination performance than commercial membrane PC-SK. Overall, the developed $\mathrm{CINH} 2$ membranes are suitable for water desalination and other separation processes.

\section{ORCID}

Walid Mabrouk (D) https://orcid.org/0000-0002-6671-794X

\section{REFERENCES}

1. Van Beek LPH, Wada Y, Bierkens MFP. Global monthly water stress: 1. Water balance and water availability. Water Resour. Res. 2011;47: 1-25.

2. Dickson SE, Schuster-Wallace CJ, Newton JJ. Water security assessment indicators: the rural context. Water Resour Manage. 2016;30: 1567-1604.

3. Mekonnen MM, Hoekstra AY. Four billion people facing severe water scarcity. Sci Adv. 2016;2:1-6.

4. Nazemi A, Madani K. Urban water security: emerging discussion and remaining challenges. Sustainable Cities Soc. 2018;41:925-928.

5. Turek M. Cost effective electrodialytic seawater desalination. Desalination. 2002;153:371-376.

6. Streit KF, Gerevini GG, Rodrigues MAS, Ferreira JZ, Bernardes AM, de Pinho MN. Electrodialysis in an integrated NF/ED process for water recovery in the leather industry. Sep Sci Technol. 2013;48: 445-454.

7. Strathmann H. Electrodialysis, a mature technology with a multitude of new applications. Desalination. 2010;264:268-288.

8. Imran Khan M, Zheng C, Mondal AN, et al. Preparation of anion exchange membranes from BPPO and dimethylethanolamine for electrodialysis. Desalination. 2017;402:10-18.

9. Vogel C, Meier-Haack J. Preparation of ion-exchange materials and membranes. Desalination. 2014;342:156-174.

10. Burn S, Hoang M, Zarzo D, et al. Desalination techniques - A review of the opportunities for desalination in agriculture. Desalination. 2015;364:2-16.

11. Cheng C, White N, Shi H, Robson M, Bruening ML. Cation separations in electrodialysis through membranes coated with polyelectrolyte multilayers. Polymer. 2014;55:1397-1403.

12. Ergun E, Tor A, Cengelolu Y, Kocak I. Electrodialytic removal of fluoride from water: effect of process parameters and accompanying anions. Sep Purif Technol. 2008;64:147-153.

13. Zhang W, Miao M, Pan J, et al. Separation of divalent ions from seawater concentrate to enhance the purity of coarse salt by electrodialysis with monovalent selective membranes. Desalination. 2017;411: 28-37.

14. Vinodh R, llakkiya A, Elamathi S, Sangeetha D. A novel anion exchange membrane from polystyrene (ethylene butylene) polystyrene: synthesis and characterization. Mater Sci Eng B. 2010;167: 43-50. 
15. Zhang Z, Chalkova E, Fedkin M, et al. Synthesis and characterization of poly(vinylidene fluoride)-g-sulfonated polystyrene graft copolymers for proton exchange membrane. Macromolecules. 2008;41: 9130-9139.

16. Nagarale RK, Gohil GS, Shahi VK. Recent developments on ionexchange membranes and electro-membrane processes. Adv. Colloid Interface Sci. 2006;119:97-130.

17. Zheng $\mathrm{H}$, Luo $\mathrm{H}$, Mathe $\mathrm{M}$. Proton exchange membranes based on poly(2,5-benzimidazole) and sulfonated poly(ether ether ketone) for fuel cells. J Power Sources. 2012;208:176-179.

18. Mabrouk W, Ogier L, Matoussi F, et al. Preparation of new proton exchange membranes using sulfonated poly(ether sulfone) modified by octylamine (S-PESOS). Mater Chem Phys. 2011;128:456-463.

19. Mabrouk W, Ogier L, Vidal S, Sollogoub C, Matoussi F, Fauvarque JF. Ion exchange membranes based upon crosslinked sulfonated polyethersulfone for electrochemical applications. J Membr Sci. 2014;452: 263-270.

20. Adiga SP, Jin C, Curtiss LA, Monteiro-Riviere NA, Narayan R. Nanoporous membranes for medical and biological applications. Wiley Interdiscip Rev Nanomed Nanobiotechnol. 2009;1:568-581.

21. Jessie Lue S, Joshua Wang F, Hsiaw S-Y. Pervaporation of benzene/cyclohexane mixtures using ion-exchange membrane containing copper ions. J Membr Sci. 2004;240:149-158.

22. Mabrouk W, Ogier L, Vidal S, et al. Synthesis and characterization of polymer blends of sulfonated polyether sulfone and sulfonated polyether sulfone octylsulfonamide for PEMFC applications. Fuel Cells. 2012;2:179-187.

23. Merle G, Wessling $M$, Nijmeijer $K$. Anion exchange membrane for alkaline fuel cells: a review. J Membr Sci. 2011;377:1-35.

24. Hickner MA. Ion containing polymers: new energy and clean water. Mater Today. 2010;13:34-41.

25. Padaki $M$, Isloor AM, Wanichapichart $P$, Ismail AF. Preparation and characterization of sulfonated polysulfone and N-phthloyl chitosan blend composite cation exchange membrane for desalination. Desalination. 2012;298:42-48.

26. Tanaka Y. Ion exchange membrane electrodialysis for saline water desalination and its application to seawater concentration. Ind Eng Chem Res. 2011;50:7494-7503.

27. Carmo M, Fritz DL, Mergel J, Stolten D. A comprehensive review on PEM water electrolysis. Int J Hydrogen Energy. 2013;38:4901-4934.

28. Zhai Z, Zhao N, Liu J, et al. Advanced nanofiltration membrane fabricated on the porous organic cage tailored support for water purification application. Sep Purif Technol. 2020;230:115845-115853.

29. Khayet M. Membrane surface and characterization by X-ray photoelectron spectroscopy, atomic force microscopy and contact angle measurements. Appl Surf Sci. 2004;238:269-272.
30. Zheng Y, Ash U, Pandey RP, et al. Water uptake study and anion exchange membranes. Macromolecules. 2018;51:3264-3278.

31. Duan O, Ge S, Wang CY. Water uptake, ion conductivity and swelling properties of anion exchange membrane. J Power Sources. 2013;243: 773-778.

32. Mabrouk W, Ogier L, Sollogoub C, Vidal S, Matoussi F, Fauvarque JF. Synthesis and characterization of new membranes deriving from sulfonated polyethersulfone for PEMFC applications. Desalin. Water Treat. 2015;56:1-9.

33. Agel E, Bouet J, Fauvarque JF. Characterization and use of anionic membranes for alkaline fuel cells. J Power Sources. 2001;101:267-274.

34. Olsson JS, Pham TH, Jannasch P. Poly(acrylene piperidinium) hydroxide ion exchange membranes: synthesis, alkaline stability and conductivity. Adv Funct Mater. 2018;28:1-10.

35. La Cerva M, Gurreri L, Tedesco M, et al. Determination of limiting current density and current efficiency in electrodialysis units. Desalination. 2018;445:138-148.

36. Geraldes $\mathrm{V}$, Afonso MD. Limiting current density in the electrodialysis of multi-ionic solutions. J Membr Sci. 2010;360:499-508.

37. Doyen A, Roblet C, L'Archevêque-Gaudet A, Bazinet L. Mathematical sigmoid-model approach for the determination of limiting and overlimiting current density values. J Membr Sci. 2014;452:453-459.

38. Ali MBS, Mnif A, Hamrouni B, Dhahbi M. Denitrification of brackish water by electrodialysis: effect of process parameters and water characteristics. Surf Eng Appl Electrochem. 2010;46:253-262.

39. Aguado D, Montoya T, Ferrer J, Seco A. Relating ions concentration variations to conductivity variations in a sequencing batch reactor operated for enhanced biological phosphorus removal. Environ Modell Software. 2006;21:845-851.

40. Lumb A, Sharma TC, Bibeault JF. A review of Genesis and Evolution of Water Quality Index (WQI) and some future directions. Water Qual., Exposure Health. 2011;3:11-24.

41. Lazarova V, Levine B, Sack J, et al. Role of water reuse for enhancing integrated water management in Europe and Mediterranean countries. Water Sci Technol. 2001;43:25-33. 